\title{
Editorials
}

\section{Stigma and discrimination against people with mental illness: a critical appraisal}

\author{
CHRISTOPH LAUBER
}

\begin{abstract}
This editorial gives an overview of the different roots and forms of discrimination and stigmatisation towards people with mental illness. It explains the differences between stereotype, prejudice and discrimination. It further highlights some research foci of stigma research in the last decade. The emphasis was mostly on investigating the attitudes of the general population, but barely addressed other groups that have probably more intensive and more crucial contact with people with mental illness. Furthermore, only very few intervention programs were evaluated. This editorial concludes that other groups than the general population, e.g., mental health professionals, should be investigated about their attitudes to people with mental illness. Moreover, intervention campaigns should be additionally evaluated after a given period as it is not well known whether effects of interventions are long-lasting. It might be that anti-stigma campaigns, as every public health campaign, must be repeated if sustainability is the goal. Furthermore, the message must be carefully chosen. One option is to replace the "traditional" messages by focussing, e.g., on symptoms of mental illness, for instance anxiety, affective symptoms or suicidal ideations. Finally, a plea for more stigma-related research is given as research in stigma-related issues is also stigmatised.
\end{abstract}

\section{DIFFERENT FACETS OF STIGMA}

Stigma and discrimination towards people with mental illness is a well-known and long-lasting phenomenon. The expression "stigma" is of Greek origin and means a small spot, mark or scar and was primarily used in burnmarking animals with an individual sign to indicate that they belong to the same herd or owner. In these days, however, the common understanding of stigma is a severe social disapproval due to believed or actual individual characteristics, beliefs or behaviours that are against norms, be they economic, political, cultural or social. They occur on an individual as well as on a societal level.

We must distinguish between different terms that are, however, used mutually in every day life: Stereotypes are defined as an attitude towards a group or an individual due to real or assumed characteristics while prejudices refer to emotional reactions to a certain attitude. The term discrimination is used for the behavioural response to a prejudice, e.g., concrete actions taken such as being treat-

Address for correspondence: Professor C. Lauber, Division of Psychiatry, University of Liverpool, Duncan Building, Royal Liverpool University Hospital, Liverpool L69 3GA (United Kingdom).

Fax: +44-151-706-5892

E-mail: christoph.lauber@liverpool.ac.uk

Declaration of Interest: None. ed unfairly or denied opportunities. Finally, stigmatisation is used as a universal term for excluding and discriminating people.

Economic and social minorities including cultural, political and religious ones or people with health handicaps are affected by stigma and discrimination. Well-known examples of economic discrimination are job wages which usually are higher for men compared to women. Cultural discrimination can be found among ethnic minorities, e.g., among non-White people in a society dominated by whites. Other examples of social discrimination can be seen towards religious minorities such as Jews or Muslims. Sexual orientation can lead to social discrimination as well. Concerning discrimination due to health problems, commonly known is discrimination due to physical handicaps. However, in the last couple of years, several initiatives helped people with physical disabilities to overcome their discrimination. People with paraplegia for instance built up a lobby that helps them claiming their rights. Likewise organisations exist for people with multiple sclerosis, diabetes mellitus and other chronic and disabling conditions.

\section{STIGMATISATION OF PEOPLE WITH MENTAL ILLNESS}

However, people with mental illness are an exception. They have no real lobby to fight for them, to claim and 
defend their rights and to protect them against injustice and discrimination. The question is why these people are different from, e.g., people with multiple sclerosis. There are some explications, but honestly we only do know little about underlying reasons. Even less is known when it comes to strategies to fight against stigma and discrimination.

The simplest explication can be found in research results collected over the last decades. These findings reveal that the general population holds many negative attitudes and prejudices towards those affected. These people are stigmatised due to their individual characteristics and their behaviour. The general population regards the social interaction with them as strange and uncomfortable while their behaviour is seen as unpredictable, dangerous and violent.

\section{PERSPECTIVES IN STIGMA-RELATED RESEARCH}

Research so far focused on what attitude the general population has towards people with mental illness. As attitudes are very much depending on culture, research was performed in different countries across various cultural settings. There are even some findings available over time (Phelan \& Link, 1998). This wide range of results can be summarised as follows: the public generally holds negative views of people with mental illness (Lauber et al., 2000; 2002). This is shown by mostly negative or at least false stereotypes (Lauber et al., 2003a). One common belief is that people with mental illness - irrespective of the underlying disorder - are dangerous, unpredictable and violent (Lauber et al., 2006a). This might be true for certain disorders, especially in their acute phase, but is not a general characteristic of people with mental illness. This negative attitude has devastating consequences. On an individual level, it leads to social distance, i.e. people are not ready to socially interact with those affected which may lead to their social exclusion (Graf et al., 2004; Lauber et al., 2004a; Müller et al., 2006; 2007; in press; Nordt et al., 2007). On a structural or societal level, negative views and attitudes are related to discrimination, e.g., in equal civil rights, in medical insurance coverage, in parenting or serving jury duty, in access to housing or employment, or in the reliance on jails, prisons and homeless shelters as the focus of care for the most severely ill (Burns et al., 2007; Lauber et al., 2005a; 2006b, c). Furthermore, significant other of people with mental illness are stigmatised and burdened (Lauber et al., 2003b; 2005b).These are tangible manifestations of stigma related to mental illness.
We additionally found in the general population that more social distance is associated with the belief that treatment with complementary and alternative medicine is more appropriate for people with mental illness compared to standard psychiatric therapy such as medication for instance (Lauber et al., 2001; 2003c; 2005c). This is a real challenge for anti-stigma endeavours as more social distance signifies, at the end, that inappropriate therapies are supported whereas more social distance leads to the support of adequate and effective therapeutic procedures.

A vicious circle of wrong or lacking knowledge about causes, treatment possibilities and consequences of mental illness, discriminating attitudes and prejudices towards people with mental illness and, finally, discrimination of these people leads to disadvantage, ostracism, exclusion and banishment of those affected and their relatives, but also of psychiatry and its professionals.

Although stigmatisation from the general population is very important, we additionally investigated a particular group of people who are in daily contact with people with mental illness, namely professionals in psychiatry (Lauber et al., 2004b; 2005d; 2006a). We compared these results with a survey conducted some years earlier among the general population in Switzerland. The findings were surprising and, in a way, alarming. Attitudes of mental health professionals did not very much differ from those found in the general population. E.g., stereotypes were highest in psychiatrists, compared to the general population and to other mental health professionals such as nurses, social workers etc. The social distance of mental health professionals towards people with mental illness does not really differ from that of the general public. We also could confirm the finding already known from the general public that people with schizophrenia evoke more social distance than people with depression.

We also studied the knowledge of mental health professionals. We asked them to assess a given vignette, i.e. a short story which describes a person with a mental illness (Nordt et al., 2006). They had to indicate on whether the person depicted suffers from a mental illness or shows a normal reaction on a simple life crisis. The results for the schizophrenia vignette were unequivocal: the great part of mental health professionals said that the person depicted suffers from a mental illness. For the depression vignette, however, the findings were not that clear: although psychiatrists and psychologists mostly recognised the person in the vignette as having a mental illness, only about $2 / 3$ among the nurses and other paramedics did. This might influence the interdisciplinary work.

The fight against stigmatisation and discrimination of people with mental illness became an important issue in 
the last decade. Many initiatives in different countries all over the world were launched. National and international opinion makers and leaders engaged in this fight and several patients, relatives and professional organisations were involved. An impressive bulk of research findings and everyday life accounts were collected. Affected people, relatives, professionals and researchers contributed likewise. These activities lead to an impressive list of events, congresses, paperwork and action plans. A huge awareness was created for the stigmatisation of people with mental illness.

However, the overall results in tackling stigmatisation and discrimination of people with mental illness are difficult to measure and interpret. There are only few follow-up studies to investigate whether anti-stigma endeavours are successful and sustainable. The results are not encouraging. The effect of any anti-stigma campaign is small and not long-lasting. Campaigns "poured over the general population" have been criticised as not specific enough. These campaigns aimed at reducing negative stereotypes and attitudes towards people with mental illness. Many of them were built around the message: "Mental illness is an illness as any other somatic illness." However, this might be an erroneous assumption as research showed that the general population does not agree.

\section{CONCLUSION}

This may lead to several conclusions: first of all, antistigma campaigns, as every public health campaign, must be repeated if sustainability is the goal. The general public might be not the perfect target population as the effects of an intervention may dilute too much. Thus, specific groups rather than "the general public" must be targeted. However, the "target" population has to be chosen carefully. A confusing example are (mental) health professionals. On the one side, their professional background makes them perfect opinion leaders and role models. On the other side, their opinions and beliefs about the people they care for do not very much differ from the general population. This contradiction must be addressed before setting up anti-stigma campaigns with mental health professionals in a leading and role model position. Furthermore, the message must be carefully chosen. One option is to replace the "traditional" messages by focussing, e.g., on symptoms of mental illness, for instance anxiety, affective symptoms or suicidal ideations. This is based on the knowledge that anxiety and depressive symptoms are very common among the general population as epidemiological studies show. Additionally, more people commit suicide in Europe than die in car accidents or by murder. Using symptoms would simplify the message and at the same time communication could be based on real and everyday issues. In the case of suicidal ideations, the target populations include general practitioners, teachers, human resource managers, priests, youth workers etc. Thus, campaigns to enhance the knowledge and the evaluation of psychic symptoms could be much more beneficial than traditional anti-stigma campaigns. Furthermore, we have nowadays several tools to reintegrate people with mental illness, e.g., into the employment market (Burns et al., 2007).

We earlier said that there is a lack of research on longterm effects of anti-stigma campaigns. So this issue should be addressed as well. However, this kind of research needs a political backup in times where biological aspects in psychiatry have much higher priority than social ones.

\section{REFERENCES}

Burns T., Catty J., Becker T., Drake R.E., Fioritti A., Knapp M., Lauber C., Rössler W., Tomov T., van Busschbach J., White W., Wiersma D. \& the EQOLISE Group (2007). The effectiveness of supported employment for people with severe mental illness: a randomised controlled trial. Lancet 370, 1146-1152.

Graf J., Lauber C., Nordt C., Rüesch P., Meyer P.C. \& Rössler W. (2004). Perceived stigmatization of mentally ill people and its consequences for the quality of life in a Swiss population. Journal of Nervous and Mental Disease 192, 542-547.

Lauber C., Nordt C., Sartorius N., Falcato L. \& Rössler W. (2000). Public acceptance of restrictions on mentally ill people. Acta Psychiatrica Scandinavica 102, Supplement No. 407, 26-32.

Lauber C., Nordt C., Falcato L. \& Rössler W. (2001). Lay recommendations on how to treat mental disorders. Social Psychiatry and Psychiatric Epidemiology 36, 553-556.

Lauber C., Nordt C., Falcato L. \& Rössler W. (2002). Public attitude to compulsory admission of mentally ill people. Acta Psychiatrica Scandinavica 105, 385-389.

Lauber C., Nordt C., Falcato L. \& Rössler W. (2003a). Lay beliefs about causes of depression. Acta Psychiatrica Scandinavica 108, Supplement No. 418, 96-99.

Lauber C., Eichenberger A., Luginbühl P. \& Rössler W. (2003b). Determinants of family burden in patients with exacerbating schizophrenia. European Psychiatry 18, 285-289.

Lauber C., Nordt C., Falcato L. \& Rössler W. (2003c). Do people recognise mental illness? Factors influencing mental health literacy. European Archives of Psychiatry and Clinical Neuroscience 253, 248-251.

Lauber C., Nordt C., Falcato L. \& Rössler W. (2004a). Factors influencing social distance towards people with mental illness. Community Mental Health Journal 40, 265-274.

Lauber C., Anthony M., Ajdacic-Gross V. \& Rössler W. (2004b). What about psychiatrists' attitude to mentally ill people? European Psychiatry 19, 423-427.

Lauber C., Lay B \&, Rössler W. (2005a). Homelessness among people with severe mental illness in Switzerland. Swiss Medical Weekly 135 50-56. 
Lauber C., Keller C., Eichenberger A. \& Rössler W. (2005b). Family burden during exacerbation of schizophrenia: quantification and determinants of additional costs. International Journal of Social Psychiatry 51, 259-264.

Lauber C., Nordt C. \& Rössler W. (2005c). Lay beliefs about treatments for people with mental illness and their implications for anti-stigma strategies. Canadian Journal of Psychiatry 50, 745-752.

Lauber C., Nordt C. \& Rössler W. (2005d). Recommendations of mental health professionals and the general population on how to treat mental disorders. Social Psychiatry and Psychiatric Epidemiology 40, 835-843.

Lauber C., Nordt C., Braunschweig C. \& Rössler W. (2006a). Do mental health professionals stigmatise their patients? Acta Psychiatrica Scandinavica 113, Supplement No. 429, 51-59.

Lauber C., Lay B. \& Rössler W. (2006b). Homeless people at disadvantage in mental health services. European Archives of Psychiatry and Clinical Neuroscience 256, 138-145.

Lauber C., Nordt C., Falcato L. \& Rössler W. (2006c). Community psychiatry: results of a public opinion survey. International Journal of Social Psychiatry 52, 234-242.
Müller B., Nordt C., Lauber C., Rüesch P., Meyer P.C. \& Rössler W. (2006). Mental illness, stigma and social support: A longitudinal approach. Social Science and Medicine 62, 39-49.

Müller B., Nordt C., Lauber C. \& Rössler W. (in press). Changes in social network diversity and perceived social support after psychiatric hospitalisation: results from a longitudinal study. International Journal of Social Psychiatry.

Nordt C., Rössler W. \& Lauber C. (2006). Attitudes of mental health professionals towards people with schizophrenia and major depression. Schizophrenia Bulletin 32, 709-714.

Nordt C., Müller B., Rössler W. \& Lauber C. (2007). Predictors and course of vocational status, income, and quality of life in people with severe mental illness: a naturalistic study. Social Science and Medicine 65, 1420-1429.

Phelan J.C. \& Link B.G. (1998). The growing belief that people with mental illnesses are violent: the role of the dangerousness criterion for civil commitment. Social Psychiatry and Psychiatric Epidemiology 33, Suppl. No. 1, S7-12. 